\title{
Associations between Two Single Nucleotide Polymorphisms of Adiponectin Gene and Coronary Artery Diseases
}

\author{
Chan-Hee JUNG, Eun-Jung RHEE, Se-Yeon KIM*, Hun-Sub SHIN, BYung-Jin KIM, Ki-Chul SUNG, \\ Bum-Su KIM, WON-YOUng LEE, JiN-Ho KANG, KI-WON OH**, MAN-Ho LEE, SUN-WOO KIM \\ AND JUNG-ROE PARK \\ Department of Internal Medicine, Kangbuk Samsung Hospital, Sungkyunkwan University School of Medicine, Pyung-dong, Seoul \\ 110-746l, South Korea \\ *Research Institute of Medical Science, Kangbuk Samsung Hospital, Sungkyunkwan University School of Medicine, Pyung-dong, \\ Seoul 110-746l, South Korea \\ **Department of Internal Medicine, College of Medicine, Hallym University, Anyang-city, Kyungi-do, Pyungchon 431-070, South \\ Korea
}

\begin{abstract}
Adiponectin, an adipocyte-secreted protein, is known to have anti-atherogenic, anti-inflammatory and antidiabetic properties and its serum levels are decreased in obesity, type 2 diabetes, and coronary artery disease. Several studies have been performed to investigate the association of genetic variations in the adiponectin with obesity, insulin resistance, and type 2 diabetes, but few studies were performed in association with coronary artery disease. Therefore we examined the associations between two single nucleotide polymorphisms ( $\mathrm{SNPs}$ ), $+45 \mathrm{~T}>\mathrm{G}$ and $+276 \mathrm{G}>\mathrm{T}$ of the adiponectin gene, and coronary artery diseases (CAD). One hundred and fifty six subjects (mean age 57.4 yrs) were enrolled in which coronary angiograms were performed due to chest pain. Genotypings were done for two SNPs in the adiponectin gene by Taqman polymerase chain reaction (PCR) method. The presence of CAD was defined as a $>50 \%$ reduction of coronary artery diameter. Among 156 subjects, the allele frequencies were 0.683 for $\mathrm{G}$ allele and 0.317 for $\mathrm{T}$ allele in $\mathrm{SNP}+276 \mathrm{G}>\mathrm{T}$ and 0.705 for $\mathrm{T}$ allele and 0.295 for $\mathrm{G}$ allele in $\mathrm{SNP}+45 \mathrm{~T}>\mathrm{G}$. Both genotypes were in compliance with Hardy-Weinberg equilibrium. No association with the presence of CAD was observed for adiponectin gene SNP276 and SNP45 ( $p=0.954, p=0.843)$. Also, no significant association was observed between the severity of CAD and either SNPs $(p=0.571, p=0.955)$. Our study showed that $\mathrm{SNP}+276 \mathrm{G}>\mathrm{T}$ and $+45 \mathrm{~T}>\mathrm{G}$ in adiponectin gene were not associated with the presence of CAD. Further studies will be necessary to confirm the role of SNP $276 \mathrm{G}>\mathrm{T}$ and $45 \mathrm{~T}>\mathrm{G}$ in the development of CAD.
\end{abstract}

Key words: Adiponectin, Single nucleotide polymorphism, Coronary artery disease

(Endocrine Journal 53: 671-677, 2006)

IN industrialized societies, cardiovascular diseases are the leading cause of death. They develop by the interaction of diverse environmental factors and genetic factors, the major causality being atherosclerosis [1]. Adiponectin is a recently discovered adipocytokine that is specifically and highly expressed in human adi-

Received: January 30, 2006

Accepted: June 21, 2006

Correspondence to: Eun Jung RHEE, M.D., Division of Endocrinology and Metabolism, Department of Internal Medicine, Kangbuk Samsung Hospital, Sungkyunkwan University School of Medicine, \#108 Pyung-Dong, Jongro-Ku, Seoul 110-746, Korea pose tissue, and is one of the mostly abundant protein in circulation in human body $[2,3]$. Plasma adiponectin level has been reported to be decreased in the conditions of obesity and type 2 diabetes. Administration of synthetic adiponectin reduces the serum glucose level in both normal and diabetic rat models, and is thought to play an important role in insulin resistance, obesity, and diabetes in rats with obesity-induced insulin resistance [4-6]. Sakuta et al. have reported that plasma levels of adiponectin were associated positively with HDL-C and age and inversely with body mass index and $\mathrm{HbA} 1 \mathrm{C}$ in Japanese men with type 2 diabetes [7]. Ouchi et al. have reported that in 42 patients with coro- 
nary artery diseases, serum adiponectin concentration was significantly lower than control group, and significantly low concentrations were detected in the association with the cardiovascular risk factors, for example, hypertension, obesity and type 2 diabetes [8]. In addition, in males with coronary artery diseases, subjects with hypoadiponectinemia showed 2 times higher risk for coronary artery diseases independent of the effects of other cardiovascular risk factors than those with normal serum adiponectin level [9].

In a few recent in vitro studies, adiponectin has been considered to inhibit the TNF- $\alpha$-induced monocyte adhesion to the aortic endothelium, to suppress the expression of various adhesion molecules and the class A macrophage scavenger receptor, and to inhibit the macrophages from forming foamy cells as well as to inhibit vascular smooth muscle cell proliferation and migration, through which it has anti-inflammatory and antiatherogenic properties $[8,10]$. In animal studies, adiponectin-deficient mice exhibited severe endothelial thickening of artificially injured arteries and showed smooth muscle cell proliferation and the supplementation of adiponectin by adenovirus transfection clearly improved neointimal proliferation in this injured model, which suggest that the advanced vascular injury was the direct effect of adiponectin deficiency $[11,12]$.

Human adiponectin gene, referred to as $A P M 1$, is located in the chromosome 3q27 that is known to be the susceptibility locus for metabolic syndrome and type 2 diabetes, and is encoded by 3 exons which spans approximately $16 \mathrm{~kb}[13,14]$. It shares structural similarities with complement protein $\mathrm{C}_{1 \mathrm{q}}$ and the TNF family that have been known to play an important role in inflammation, immune system, and arteriosclerosis [15, 16]. In the genome-wide scan performed in Japanese and Caucasians, more than 10 single nucleotide polymorphisms were reported, and among them, the genetic polymorphism of +45 in the exon 2 and +276 in the intron 2 have been frequently referred to be in association with type 2 diabetes and obesity [17-21]. Recently, several studies have been reported in association of adiponectin SNPs with coronary artery disease, although those in Asians are scarce.

Therefore, we investigated whether the two SNPs of adiponectin gene, that is, $+276 \mathrm{G}>\mathrm{T}$ in intron 2 and $+45 \mathrm{~T}>\mathrm{G}$ in exon 2 , are associated with the presence of coronary artery diseases in Korean subjects who underwent coronary angiograms.

\section{Materials and Methods}

\section{Subjects and Measurements}

156 subjects were enrolled in which coronary angiograms were performed due to chest pain in Kangbuk Samsung Hospital from April to August, 2003 (97 males, 59 females, mean age $57.40 \pm 11.15$ years). The patients with acute infectious diseases, chronic kidney disease (creatinine $\geq 2.0 \mathrm{mg} / \mathrm{dL}$ ), osteoporosis, malignant tumor, and other medical diseases were excluded from the study population. Written informed consent was obtained from each participant and the study protocol conforms to the ethical guidelines of the 1975 Declaration of Helsinki as reflected in a priori approval by the institution's human research committee.

Height, weight, waist circumference and systolic and diastolic blood pressures were measured in duplicate and the results were averaged. Weight and height were measured in $\mathrm{Kg}$ and $\mathrm{cm}$, respectively, down to two decimal points. The body mass index (BMI) was calculated by dividing the weight $(\mathrm{Kg})$ with the square of height (m).

After 12 hours of fasting, blood sampling was done. Fasting blood glucose, total cholesterol, triglyceride, HLD-C, and LDL-C were measured from the samples and the hexokinase method was used to measure blood glucose levels and enzymatic calorimetric test was used to measure the total cholesterol and triglyceride levels. The selective inhibition method was used to measure the level of HDL-C and the homogeneous enzymatic calorimetric test was used to measure the level of LDL-C.

Coronary artery angiography was performed in all patients. Significant stenosis was defined as the internal diameter decreased by more than $50 \%$. Patients were grouped according to the number of significantly stenotic vessels into normal, 1-vessel, 2-vessel and 3vessel diseased groups.

Genotyping of adiponectin polymorphisms of $+276 G>T$ in intron 2 and $+45 T>G$ in exon 2 by realtime polymerase chain reaction $(P C R)$

The buffy coat was obtained from blood samples, refrigerated at $-70^{\circ} \mathrm{C}$, and the genomic DNA was then extracted using Takara DNA Purification kits. The genotyping of the T45G polymorphism in exon 2 and the G276T in intron 2 of the adiponectin gene was per- 
formed by employing an allelic discrimination assay and by using the TaqMan probe. The detector used in this experiment was an ABI Prism 7200 sequence detection platform (Perkin Elmer, USA). The primers and probes used were as follows.

1) $\mathrm{T} 45 \mathrm{G}$

forward primer:

5'-CAC ATG TGG ATT CCA GGG C-3'

reverse primer:

5'-CCC TTG GGC AGG GGA A-3'

FAM-labeled probe:

5'FAM-CCG GTC ATG ACC AGG3'

VIC-labeled probe:

5'VIC-TGC CCG GGC ATG A3'

2) $\mathrm{G} 276 \mathrm{~T}$

forward primer:

5'-TTC TCC CTG TGT CTA GGC CTT AGT T-3'

reverse primer:

5'-CTT TCA TCA CAG ACC TCC TAC ACT GA-3'

FAM-labeled probe:

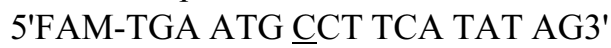

VIC-labeled probe:

5'VIC-ATA ATG AAT GÁC TTC ATA TAG TT3'

\section{Statistical method}

Statistical analysis was performed using the SPSS for Windows version 11.0. All results were presented as the mean \pm standard deviation (SD). The comparison of mean values between different coronary artery disease severity group was analyzed by Student's $t$ test. The test for Hardy-Weinberg equilibrium was performed using the $\chi^{2}$-test. The association of the genotypes of the adiponectin gene with the presence or absence of coronary artery diseases in each group was analyzed by $\chi^{2}$-test, and as a statistically significant level, $p$ value less than 0.05 was used.

\section{Results}

\section{General characteristics of the subjects}

The general characteristics of the study subjects are presented in Table 1 . In 63 cases $(65.6 \%)$ out of total 97 cases of males and 25 cases $(42.4 \%)$ out of 59 female cases, coronary artery stenosis was detected by coronary artery angiogram, which showed significantly higher prevalence of coronary artery stenosis in males $(p=0.005)$. Subjects with coronary artery was significantly older than those with normal coronary artery $(60.44 \pm 10.18$ vs $53.40 \pm 11.18, p<0.001)$, and high-density lipoprotein cholesterol level was significantly lower in subjects with coronary stenosis than those with normal coronary artery disease $(48.50 \pm$ 12.29 vs $54.34 \pm 12.30, p=0.004)$. In regard to total cholesterol, low-density lipoprotein cholesterol, triglyceride, body mass index, and fasting serum glucose, significant differences between two groups were not detected (Table 1). In the entire study population, patients with fasting serum glucose over $126 \mathrm{mg} / \mathrm{dL}$ were 34 cases out of 156 cases, the cases with over $126 \mathrm{mg} /$ $\mathrm{dL}$ who showed coronary artery stenosis were 28 patients, the group showing normal coronary arteries was

Table 1. General characteristics of CAD cases and control patients

\begin{tabular}{lcccr}
\hline & Total & CAD & Control & P \\
\hline Age (years) & $57.40 \pm 11.15$ & $60.44 \pm 10.18$ & $53.40 \pm 11.18$ & $<0.001$ \\
Gender, M/F & $97 / 59$ & $63 / 25$ & $34 / 34$ & 0.005 \\
BMI $\left(\mathrm{kg} / \mathrm{m}^{2}\right)$ & $25.34 \pm 2.88$ & $25.43 \pm 2.74$ & $25.23 \pm 3.05$ & 0.679 \\
DM & $34(21.8 \%)$ & $28(31.8 \%)$ & $6(8.8 \%)$ & 0.001 \\
IFG & $54(34.6 \%)$ & $31(57.4 \%)$ & $23(42.6 \%)$ & 0.855 \\
FPG (mg/dL) & $116.26 \pm 43.53$ & $123.39 \pm 48.84$ & $107.03 \pm 33.67$ & 0.015 \\
T-chol (mg/dL) & $200.91 \pm 47.42$ & $200.40 \pm 51.33$ & $201.58 \pm 42.10$ & 0.878 \\
TG $(\mathrm{mg} / \mathrm{dL})$ & $180.17 \pm 181.85$ & $188.91 \pm 186.63$ & $168.16 \pm 175.81$ & 0.489 \\
HDL-chol (mg/dL) & $105.20 \pm 51.01$ & $48.50 \pm 12.30$ & $54.34 \pm 12.30$ & 0.004 \\
LDL-chol (mg/dL) & $112.41 \pm 34.54$ & $112.96 \pm 34.71$ & $111.67 \pm 34.55$ & 0.819 \\
\hline
\end{tabular}

Data are means \pm SD. BMI, body mass index; DM, diabetes mellitus; IFG, impaired fasting glucose; FPG, fasting plasma glucose; T-chol, total cholesterol; TG, triglyceride; HDL-chol, high-density lipoprotein cholesterol; LDL-chol, low-density lipoprotein cholesterol 
6 patients, and a statistically significant difference was observed $(31.8 \%$ vs $8.8 \%, p=0.001)$.

Relation of adiponectin gene polymorphisms and presence of coronary artery diseases

In total 156 study subjects, in regard to the frequencies of the G276T polymorphism in intron 2 of the adiponectin gene, GG was $44.2 \%$ (69 cases), GT was $48.1 \%$ ( 75 cases), and TT was $7.7 \%$ ( 12 cases). The allele frequency was 0.683 for the $\mathrm{G}$ allele and 0.317 for the T allele, which were in compliance with HardyWeinberg equilibrium $(p=0.39)$. In addition, regarding the frequencies of the $\mathrm{T} 45 \mathrm{G}$ genotype of adiponectin exon 2, TT was $48.1 \%$ ( 75 cases), TG was $44.9 \%$ ( 70 cases), and GG was $7.1 \%$ ( 11 cases). The frequency of $\mathrm{T}$ allele was 0.705 and the frequency of $\mathrm{G}$ allele was 0.295 , which also was in compliance with HardyWeinberg equilibrium $(p=0.61)$.

Between the group with and without coronary artery diseases, the frequency of the genotype of SNP45 was not different (Table 2, $p=0.843$ ). After adjustment for other confounding CAD risk factors such as age, gender and HDL-C, there was no significant association

Table 2. Distribution of genotypes at $+45 \mathrm{G}>\mathrm{T}$ and $+276 \mathrm{~T}>\mathrm{G}$ of the adiponectin gene in CAD case and control subjects

\begin{tabular}{ccccc}
\hline \multirow{2}{r}{$\mathrm{n}$} & & Control subject & CAD patients & \\
\cline { 3 - 4 } & & 68 & 88 & \\
\hline SNP 276, & GG & $31(45.6 \%)$ & $38(43.2 \%)$ & 0.954 \\
$\mathrm{n}(\%)$ & GT & $32(47.1 \%)$ & $43(48.9 \%)$ & \\
& TT & $5(7.4 \%)$ & $7(8.0 \%)$ & \\
SNP 45, & TT & $34(50.0 \%)$ & $41(46.6 \%)$ & 0.843 \\
n (\%) & TG & $30(44.1 \%)$ & $40(45.5 \%)$ & \\
& GG & $4(5.9 \%)$ & $7(8.0 \%)$ & \\
\hline
\end{tabular}

between the frequency of the genotype SNP45 and CAD $(p=0.675)$. Similarly, concerning the frequency of SNP276 genotype, no significant difference between two groups was detected (Table $2, p=0.954$ ). Also, no significant association was detected after adjustment for age, gender and HDL-C $(p=0.880)$. Regarding the frequency of SNP 45 and SNP276 genotype according to the number of coronary arteries with stenosis, no significant difference was detected (Table $3, p=0.995, p=0.571)$.

\section{Discussion}

Among approximately 10 adiponectin gene polymorphisms reported until now, $+45 \mathrm{~T}>\mathrm{G}$ of exon 2 and $+276 \mathrm{G}>\mathrm{T}$ of intron 2 were associated with the increased risk of insulin resistance and type 2 diabetes in particular [17-20]. Numerous previous studies conferred the anti-inflammatory and anti-atherosclerotic effects of adiponectin, and strong genetic associations were reported between adiponectin and cardiovascular risk factors [8, 10, 11, 22, 23].

Several studies have been performed in regard to the association of the adiponectin polymorphisms with coronary artery diseases. Ohashi et al. examined the association of the adiponectin gene polymorphisms with the incidence of coronary artery diseases in 383 Japanese patients with confirmed coronary artery diseases by cardiovascular angiogram and compared the results with 368 controls [24]. Three SNPs were investigated, that is, I164T, SNP94, and SNP276, and they found that SNP276 and SNP94 had no associations with CAD. But the frequency of I164T was significantly higher in subjects with coronary artery disease. In addition, the serum adiponectin levels were significantly lower in individuals with the $1164 \mathrm{~T}$ mutation

Table 3. Distribution of genotypes at $+45 \mathrm{G}>\mathrm{T}$ and $+276 \mathrm{~T}>\mathrm{G}$ of the adiponectin gene among different groups according to the severity of coronary artery disease

\begin{tabular}{|c|c|c|c|c|c|c|}
\hline \multirow{2}{*}{$\mathrm{n}$} & & \multicolumn{4}{|c|}{ Number of vessels involved } & \multirow{2}{*}{$\mathrm{P}$} \\
\hline & & Normal (68) & One (49) & Two (23) & Three (16) & \\
\hline \multirow[t]{3}{*}{ SNP 276, n (\%) } & GG & $31(45.6 \%)$ & $25(51.0 \%)$ & $9(39.1 \%)$ & $4(25.0 \%)$ & 0.571 \\
\hline & GT & $32(47.1 \%)$ & $21(42.9 \%)$ & $11(47.8 \%)$ & $11(68.8 \%)$ & \\
\hline & $\mathrm{TT}$ & $5(7.4 \%)$ & $3(6.1 \%)$ & $3(13.0 \%)$ & $1(6.3 \%)$ & \\
\hline \multirow[t]{3}{*}{$\mathrm{SNP} 45, \mathrm{n}(\%)$} & $\mathrm{TT}$ & $34(50.0 \%)$ & $21(42.9 \%)$ & $12(52.2 \%)$ & $8(50.0 \%)$ & 0.955 \\
\hline & TG & $30(44.1 \%)$ & $23(46.9 \%)$ & $10(43.5 \%)$ & $7(43.8 \%)$ & \\
\hline & GG & $4(5.9 \%)$ & $5(10.2 \%)$ & $1(4.3 \%)$ & $1(6.3 \%)$ & \\
\hline
\end{tabular}


than control group. Lacquemant et al. have reported that in 162 Caucasian subjects with type 2 diabetes, $\mathrm{SNP}+45$ showed significant association with increased coronary artery disease risk whereas $\mathrm{SNP}+276$ failed to show any association [25]. On the other hand, Filippi et al. recently reported that in 325 coronary artery disease patients and 270 controls, $\mathrm{SNP}+276$ showed significant association with coronary artery disease, with odds ratio for coronary artery disease being up to 4.99 [26]. Bacci et al. have reported that in 376 Caucasian type 2 diabetes patients, SNP +276 showed significant association with coronary artery diseases, which association was independent of the serum adiponectin levels [27]. In American diabetic males, Qi et al. reported the protective effect of SNP+276 for coronary artery disease with odds ratio for coronary artery disease being 0.38 after adjustment of other confounding variables [28].

In our study, no significant associations were observed between SNP+45 and SNP+276 with the presence of coronary artery diseases. The reason for the discrepancies with the previous studies could be explained by the small sample size. Furthermore, this was the second association study next to the study by Ohashi et al., performed in Asian population analyzing the effect of adiponectin polymorphisms (I164T, SNP94, SNP276) on coronary artery disease incidence [24]. As referred above, there was no significant associations between SNP +276 and coronary artery disease in Japanese population, which is the same Asian population as our Korean population. As the allelic frequencies and the genetic effects of adiponectin gene are considered to be significantly different between Japanese and Caucasians, these discrepancies could be partly explained by ethnic differences, which needs further research in larger numbers of study subjects $[29,30]$.

Our study has several limitations. The first limitation is that as serum adiponectin level was not measured, hence the functional significance of adiponectin polymorphism cannot be assessed. However, in the previous studies, contradictory results were reported on the association of the adiponectin polymorphism with serum adiponectin levels. In the studies by Bacci et al. and Qi et al., serum adiponectin did not show association with genetic difference, and in other studies performed in Japanese, SNP276 showed significant association with plasma adiponectin levels only in the obese subgroup [27, 28, 31]. In addition, it is not so clear how serum adiponectin levels might reflect the adiponectin concentration in tissue level, such as, in the subendothelial space where the targets for the antiatherogenic effect of adiponectin are located [32-34]. Therefore, to reflect the difference of adiponectin concentration among genotypes, more specifically designed studies are required in vitro. The second limitation is that the number of study population was too small to have statistically significant power as to the association of the adiponectin polymorphism with coronary artery diseases. We have estimated the power of our study to detect a difference, should it exist, between different adiponectin polymorphisms and the presence of coronary artery disease. In the sample size of 156 subjects, a hazard ratio of 1.69 would have been detectable with $90 \%$ power and $95 \%$ confidence limits [35]. Therefore we believe that our study has reasonable power and it is unlikely that we have missed any meaningful association because of insufficient numbers. However, this study could have meaning as the first association study of adiponectin polymorphism with coronary artery disease in Koreans, and the second study in Asian population.

In summary, no significant association was observed between adiponectin polymorphisms, $+45 \mathrm{~T}>\mathrm{G}$ and $+276 \mathrm{G}>\mathrm{T}$, and coronary artery disease in Korean subjects. Further studies are warranted in the future, with larger study populations in various ethnic groups.

\section{Acknowledgement}

This work was partly supported by the Hyosuk Research Grant from Kangbuk Samsung Hospital.

\section{References}

1. Libby P, Theroux P (2005) Pathophysiology of coronary artery disease. Circulation 111: 3481-3488.

2. Scherer PE, Williams S, Fogliano M, Baldini G, Lodish HF (1995) A novel serum protein similar to
C1q, produced exclusively in adipocytes. $J$ Biol Chem 270: 26746-26749.

3. Arita Y, Kihara S, Ouchi N, Takahashi M, Maeda K, Miyagawa J (1999) Paradoxical decrease of an adipose- 
specific protein, adiponectin, in obesity. Biochem Biophys Res Commun 257: 79-83.

4. Hoffstedt J, Arvidsson E, Sjolin E, Wahlen K, Arner P (2004) Adipose tissue adiponectin production and adiponectin serum concentration in human obesity and insulin resistance. J Clin Endocrinol Metab 89: 13911396.

5. Hotta K, Funahashi T, Arita Y, Takahashi M, Matsuda M, Okamoto Y (2000) Plasma concentrations of a novel, adipose-specific protein, adiponectin, in type 2 diabetic patients. Arterioscler Thromb Vasc Biol 20: 1595-1599.

6. Weyer C, Funahashi T, Tanaka S, Hotta K, Matsuzawa Y, Pratley RE (2001) Hypoadiponectinemia in obesity and type 2 diabetes: close association with insulin resistance and hyperinsulinemia. J Clin Endocrinol Metab 86: 1930-1935.

7. Sakuta H, Suzuki T, Yasuda H, Ito T (2005) Adiponectin levels and cardiovascular risk factors in Japanese men with type 2 diabetes. Endocr J 52: 241-244

8. Ouchi N, Kihara S, Arita Y, Maeda K, Kuriyama H, Okamoto Y (1999) Novel modulator for endothelial adhesion molecules: adipocyte-derived plasma protein adiponectin. Circulation 100: 2473-2476.

9. Kumada M, Kihara S, Sumitsuji S, Kawamoto T, Matsumoto S, Ouchi N (2003) Osaka CAD Study Group. Coronary artery disease. Association of hypoadiponectinemia with coronary artery disease in men. Arterioscler Thromb Vasc Biol 23: 85-89.

10. Ouchi N, Kihara S, Arita Y, Maeda K, Kuriyama H, Okamoto Y (2001) Adipocyte-derived plasma protein, adiponectin, suppresses lipid accumulation and class A scavenger receptor expression in human monocytederived macrophages. Circulation 103: 1057-1063.

11. Matsuda M, Shimomura I, Sata M, Arita Y, Nishida M, Maeda N (2002) Role of adiponectin in preventing vascular stenosis. The missing link of adipo-vascular axis. J Biol Chem 277: 37487-37491.

12. Kubota N, Terauchi Y, Yamauchi T, Kubota T, Moroi M, Matsui J (2002) Disruption of adiponectin causes insulin resistance and neointimal formation. $J$ Biol Chem 277: 25863-25866.

13. Takahashi M, Arita Y, Yamagata K, Matsukawa Y, Okutomi K, Horie M (2000) Genomic structure and mutations in adipose-specific gene, adiponectin. Int $J$ Obes Relat Metab Disord 24: 861-868.

14. Vionnet N, Hani EI-H, Dupont S, Gallina S, Francke S, Dotte S (2000) Genomewide search for type 2 diabetessusceptibility genes in French whites: evidence for a novel susceptibility locus for early-onset diabetes on chromosome 3q27-qter and independent replication of a type 2 diabetes locus on chromosome 1q21q24. Am J Hum Genet 67: 1470-1480.

15. Maeda K, Okubo K, Shimomura I, Funahashi T, Matsuzawa Y, Matsubara K (1996) ccDNA cloning and expression of a novel adipose specific collagenlike factor, apM1 (AdiPose Most abundant Gene transcript 1). Biochem Biophys Res Commun 221: 286289.

16. Shapiro L, Scherer PE (1998) The crystal structure of a complement $1 \mathrm{q}$ family protein suggests an evolutionary link to tumor necrosis factor. Curr Biol 8: 335-338.

17. Hara K, Boutin P, Mori Y, Tobe K, Dina C, Yasuda K (2002) Genetic variation in the gene encoding adiponectin is associated with an increased risk of type 2 diabetes in the Japanese population. Diabetes 51: 536540.

18. Vasseur F, Helbecque N, Dina C, Lobbens S, Delannoy V, Gaget S (2002) Single-nucleotide polymorphism haplotypes in the both proximal promoter and exon 3 of the APM1 gene modulate adipocyte-secreted adiponectin hormone levels and contribute to the genetic for type 2 diabetes in French Caucasians. Hum Mol Genet 11: 2607-2614.

19. Stumvoll M, Tschritter O, Fritsche A, Staiger H, Renn W, Weisser M (2002) Association of the T-G polymorphism in adiponectin(exon 2) with obesity and insulin sensitivity: interaction with family history of type 2 diabetes. Diabetes 51: 37-41.

20. Menzaghi C, Ercolino T, Di Paola R, Berg AH, Warram JH, Scherer PE (2002) A haplotype at the adiponectin locus is associated with obesity and other features of the insulin resistance syndrome. Diabetes 51: 2306-2312.

21. Lee YY, Lee NS, Cho YM, Moon MK, Jung HS, Park YJ (2003) Genetic association of adiponectin polymorphisms with risk of type 2 diabetes mellitus. $J$ Kor Diabetes Assoc 27: 438-448.

22. Francke S, Manraj M, Lacquemant C, Lecoeur C, Lepretre F, Passa P (2001) A genome-wide scan for coronary heart disease suggests in Indo-Mauritians a susceptibility locus on chromosome $16 \mathrm{p} 13$ and replicates linkage with the metabolic syndrome on $3 \mathrm{q} 27$. Hum Mol Genet 10: 2751-2765.

23. Kissebah AH, Sonnenberg GE, Myklebust J, Goldstein M, Broman K, James RG (2000) Quantitative trait loci on chromosomes 3 and 17 influence phenotypes of the metabolic syndrome. Proc Natl Acad Sci USA 97: 14478-14483.

24. Ohashi K, Ouchi N, Kihara S, Funahashi T, Nakamura T, Sumitsuji S (2004) Adiponectin I164T Mutation is associated with the metabolic syndrome and coronary artery disease. J Am Coll Cardiol 43: 1195-1200.

25. Lacquemant C, Froguel P, Lobbens S, Izzo P, Dina C, Ruiz J (2004) The adiponectin gene SNP+45 is associated with coronary artery disease in type 2 (noninsulin-dependent) diabetes mellitus. Diabet Med 21: 776-781.

26. Filippi E, Sentinelli F, Romeo S, Arca M, Berni A, Tiberti C (2005) The adiponectin gene SNP+276G $>$ T 
associates with early-onset coronary artery disease and with lower levels of adiponectin in younger coronary artery disease patients (age $</=50$ years). $J$ Mol Med 5: 1432-1440.

27. Bacci S, Menzaghi C, Ercolino T, Ma X, Rauseo A, Salvemini L (2004) The $+276 \mathrm{G} / \mathrm{T}$ single nucleotide polymorphism of the adiponectin gene is associated with coronary artery disease in type 2 diabetic patients. Diabetes Care 27: 2015-2020.

28. Qi L, Li T, Rimm E, Zhang C, Rifai N, Hunter D, Doria A, Hu FB (2005) The +276 polymorphism of the APM1 gene, plasma adiponectin concentration, and cardiovascular risk in diabetic men. Diabetes 54: 1607-1610.

29. Lindsay RS, Funahashi T, Krakoff J, Matsuzawa Y, Tanaka S, Kobes S (2003) Genome-wide linkage analysis of serum adiponectin in the Pima Indian population. Diabetes 52: 2419-2425.

30. Comuzzie AG, Funahashi T, Sonnenberg G, Martin LJ, Jacob HJ, Black AE (2001) The genetic basis of plasma variation in adiponectin, a global endophenotype for obesity and the metabolic syndrome. J Clin Endocrinol
Metab 86: 4321-4325.

31. Hara K, Boutin P, Mori Y, Tobe K, Dina C, Yasuda K (2002) Genetic variation in the gene encoding adiponectin is associated with an increased risk of type 2 diabetes in the Japanese population. Diabetes 51: 536 540 .

32. Kubota N, Terauchi Y, Yamauchi T, Kubota T, Moroi M, Matsui J (2002) Disruption of adiponectin causes insulin resistance and neointimal formation. $J$ Biol Chem 277: 25863-25866.

33. Matsuda M, Shimomura I, Sata M, Arita Y, Nishida M, Maeda N (2002) Role of adiponectin in preventing vascular stenosis: the missing link of adipo-vascular axis. J Biol Chem 277: 37487-37491.

34. Okamoto Y, Arita Y, Nishida M, Muraguchi M, Ouchi N, Takahashi M (2000) An adipocyte-derived plasma protein, adiponectin, adheres to injured vascular walls. Horm Metab Res 32: 47-50.

35. Piantadosi S (1997) Sample size and power. In Clinical trials: A Methodologic Perspective. John Wiley and Sons, New York, pp. 148-183. 